\title{
Novel electrically conductive polyurethane/montmorillonite-polypyrrole nanocomposites
}

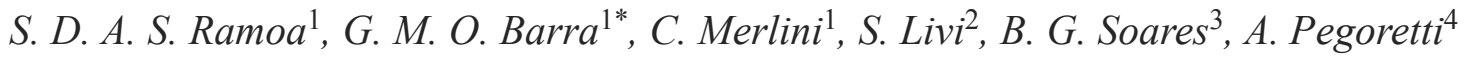 \\ ${ }^{1}$ Universidade Federal de Santa Catarina, Departamento de Engenharia Mecânica, Florianópolis, SC, Brazil \\ ${ }^{2}$ Université de Lyon, Ingénierie des Matériaux Polymères, CNRS, UMR 5223, F-69003, Lyon, France; INSA Lyon, \\ F-69621, Villeurbanne, France \\ ${ }^{3}$ Universidade Federal do Rio de Janeiro, Departamento de Engenharia Metalúrgica e de Materiais, Rio de Janeiro, RJ, Brazil \\ ${ }^{4}$ Department of Industrial Engineering, University of Trento, 38123 Trento, Italy
}

\begin{abstract}
This work describes the production of electrically conductive nanocomposites based on thermoplastic polyurethane (TPU) filled with montmorillonite-dodecylbenzenesulfonic acid-doped polypyrrole (Mt-PPy.DBSA) prepared by melt blending in an internal mixer. The electrical conductivity, morphology as well as the rheological properties of TPU/MtPPy.DBSA nanocomposites were evaluated and compared with those of TPU nanocomposites containing different conductive fillers, such as polypyrrole doped with hydrochloride acid (PPy.Cl) or dodecylbenzenesulfonic acid (PPy.DBSA) or montmorillonite-hydrochloride acid-doped polypyrrole (Mt-PPy.Cl), prepared with the same procedure. The TPU/MtPPy.DBSA nanocomposites display a very sharp insulator-conductor transition and the electrical percolation threshold was about $10 \mathrm{wt} \%$ of Mt-PPy.DBSA, which was significantly lower than those found for TPU/Mt-PPy.Cl, TPU/PPy.Cl and TPU/PPy.DBSA. Morphological analysis highlights that Mt-PPy.DBSA filler was better distributed and dispersed in the TPU matrix, forming a denser conductive network when compared to Mt-PPy.Cl, PPy.Cl and PPy.DBSA fillers. This morphology can be attributed to the higher site-specific interaction between TPU matrix and Mt-PPy.DBSA. The present study demonstrated the potential use of Mt-PPy.DBSA as new promising conductive nanofiller to produce highly conductive polymer nanocomposites with functional properties.
\end{abstract}

Keywords: nanocomposites, polymer composites, rheology

\section{Introduction}

Since its discovery in the late 1970 s, the scientific interest in understanding physical and chemical properties of the intrinsically conducting polymers (ICPs) has been increasing due to their potential in various technological applications. Among ICPs, polypyrrole (PPy) is a particularly promising material because of its high electrical conductivity, chemical and environmental stability in the oxidized state, low ionization potential, electrorheological properties, electrochromic effect and relatively easy of synthesis [1-6]. In fact, PPy can be potentially used in new advanced technology areas, including electronic and optoelectronic nanodevices [7], sensors [813], supercapacitors $[14,15]$, energy storage devices $[1,7,16]$, surface coatings for corrosion protection [17], electromagnetic shielding applications [18-20], smart textiles $[21,22]$ and even in medical applications [4, 23-26].

However, the poor mechanical performances and the difficult processability (insolubility and infusibility) $[2,3,19,20,27,28]$ have hampered the use of PPy for technological applications. Intensive investigations have been carried out to solve these problems.

\footnotetext{
*Corresponding author, e-mail: g.barra@ufsc.br

(C) BME-PT
} 
One approach to possibly overcome the above limitations is blending PPy with commercial insulating polymers to produce conductive polymer blends or composites [3, 11, 27, 29-33]. Among the methods mentioned in the scientific literature, melt mixing offers the advantages of large-scale production and reduced cost which are the bases for any industrial application. However, this process has been reported to be less efficient on the dispersion of PPy or other ICPs within insulating polymer matrices. In fact, the production of conducting polymer mixtures with electrical conductivity less than $10^{-7} \mathrm{~S} \cdot \mathrm{cm}^{-1}$, percolation threshold about 30 to $60 \mathrm{wt} \%$ of ICP and poor mechanical properties has been reported [3438]. Therefore, a great challenge is how to produce a conducting polymer mixture through melt blending process with higher electrical conductivity at low percolation threshold of ICP. Some works in the literature have demonstrated that montmorillonite/polypyrrole (Mt-PPy) nanocomposites are potential fillers for improving the electrical and mechanical properties of insulating matrix $[27,36$, 38]. According to Boukerma et al. [36], the exfoliation of Mt-PPy promotes a conductive network formation in the insulating matrix with lower PPy concentration when compared with that found for neat PPy. Mravčáková et al. [38] have reported interesting results concerning the preparation of polypropylene/Mt-PPy composites. On the other hand, Peighambardoust and Pourabbas reported that percolation threshold of Nylon-6/Mt-PPy composites was $15 \mathrm{wt} \%$ of Mt-PPy [27].

In this context, thermoplastic polyurethane (TPU) is an interesting insulating matrix for developing flexible conductive Mt-PPy composites with high electrical conductivity at low percolation threshold. TPU is among the most versatile engineering thermoplastics since it associates the properties of thermoplastic polymers with those of vulcanized rubbers without vulcanizing agents $[39,40]$. Moreover, to the best of our knowledge, there are no studies concerning the preparation of TPU composites with Mt-PPy through melt blending method.

Based on the above considerations, the main objective of this study is to investigate TPU/Mt-PPy.DBSA nanocomposites produced by melt blending and containing various filler contents. In particular, the attention has been focused on obtaining good electrical conductivity at low filler concentration. For comparison purpose, three different conductive fillers, such as polypyrrole doped hydrochloride acid (PPy.Cl) or dodecylbenzenesulfonic acid (PPy.DBSA) and montmorillonite-polypyrrole doped hydrochloride acid (Mt-PPy.Cl) were separately added into TPU matrix under the same processing conditions. The morphology, electrical and rheological properties of nanocomposites were experimentally investigated.

\section{Experimental}

\subsection{Materials}

Sodium bentonite, Vulgel CN 45 (Aliança Latina Indústrias e Comércio Ltda, Uruguaiana, Rio Grande do Sul, Brazil)) was kindly supplied by Ioto International (Brazil). Pyrrole, 98\%, (Aldrich, Germany) was purified by distillation under reduced pressure and stored in a refrigerator before use. Iron(III) chloride hexahydrate, $\mathrm{FeCl}_{3} \cdot 6 \mathrm{H}_{2} \mathrm{O}$, analytical grade (Vetec, Duque de Caxias, Rio de Janeiro, Brazil), and the surfactant dodecylbenzenesulfonic acid, DBSA, (Aldrich, Italy) were used as received. Commercially available TPU (Elastollan ${ }^{\circledR} 1180$ A10 extrusion

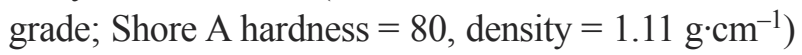
based on polyether was purchased from BASF (Mauá, São Paulo, Brazil).

\subsubsection{Synthesis of conducting nanocomposites (Mt/PPy)}

The preparation procedure of the conducting nanocomposites Mt-PPy with or without a surfactant was based on the method described in our previous report with some modifications [41]. In a typical procedure, Mt $(2.5 \mathrm{~g})$ was dispersed into $250 \mathrm{~mL}$ of water or aqueous solution containing the DBSA and stirred for $2 \mathrm{~h}$ at room temperature. The molar ratio of the surfactant/Py used in the polymerization was 1:5. The dispersion was sonicated with $35 \%$ power $(263 \mathrm{~W})$ for 20 min with a Sonics VCX 750 ultrasonic processor (Sonics \& Materials, Inc., USA). $\mathrm{FeCl}_{3} \cdot 6 \mathrm{H}_{2} \mathrm{O}(0.2542 \mathrm{~mol})$ dissolved in $125 \mathrm{~mL}$ of distilled water was added in the aqueous MMT dispersion under stirring at room temperature. $50 \mathrm{~mL}$ of a $0.26 \mathrm{~mol} \cdot \mathrm{L}^{-1}$ aqueous dispersion of Py (0.1105 $\left.\mathrm{mol}\right)$ were added dropwise in $15 \mathrm{~min}$. The polymerization proceeded for $1 \mathrm{~h}$ under stirring at room temperature. After $24 \mathrm{~h}$, the conducting fillers, (MtPPy.Cl and Mt-PPy.DBSA) were filtered, washed with distilled water and dried at $60^{\circ} \mathrm{C}$. The PPy with or without surfactant, denoted as PPy.DBSA and PPy. $\mathrm{Cl}$, respectively, were also prepared using a similar procedure. 


\subsubsection{Preparation of TPU/Mt-PPy nanocomposites}

Before processing, both TPU pellets and conducting fillers were dried in a circulating-air oven at $100^{\circ} \mathrm{C}$ for $3 \mathrm{~h}$ and vacuum oven at $60^{\circ} \mathrm{C}$ for $12 \mathrm{~h}$, respectively. TPU were melt blended with different amounts of conducting fillers $(5,10,15,20,25$ and $30 \mathrm{wt} \%)$ in an internal mixer (Haake Polylab QC, Thermo Scientific, USA) at $170^{\circ} \mathrm{C}$ with a rotor speed of $50 \mathrm{rpm}$ and mixing time of $15 \mathrm{~min}$. The specimens were compression-molded at $170^{\circ} \mathrm{C}$ for 5 min under $12 \mathrm{MPa}$ pressure, and air cooled to room temperature.

\subsection{Characterization}

The elemental analysis was used to determine the composition of conducting mixtures. Elemental analysis was performed on a CHN 2400 analyzer (Perkin-Elmer, USA). The combustion process was carried out at $925^{\circ} \mathrm{C}$ using oxygen with a purity level of $99.995 \%$.

The electrical conductivity of the conducting fillers and low-resistivity TPU composites were measured using the four probe standard method with a Keithley 6220 (USA) current source to apply the current and a Keithley Model 6517A (USA) electrometer to measure the potential difference. For neat TPU and high-resistivity composites, the measurements were performed using the two probe standard method with a Keithley 6517A (USA) electrometer connected to Keithley 8009 (USA) test fixture. All measurements were performed at room temperature and repeated at least five times for each sample.

Fracture surfaces of composites were observed by a field emission scanning electron microscope (FESEM), JEOL model JSM-6701F (JEOL, USA). The specimens were fractured in liquid nitrogen and coated with gold, and then the cross-section was observed at an accelerating voltage of $10 \mathrm{kV}$.

Transmission electron microscopy (TEM) observations were performed by a Phillips CM120 micro- scope (Phillips, Germany) (located at the Center of Microstructure University of Lyon) at $80 \mathrm{kV}$. Specimens consisting of $60 \mathrm{~nm}$-thick ultrathin sections were obtained by a Leica Ultracut UCT ultramicrotome (Leica, Germany) equipped with a diamond knife and deposited on copper grids.

Fourier transform infrared (FTIR) spectra were obtained through the attenuated total reflectance (ATR) method using a spectrometer Bruker Tensor 27 (Bruker, USA) with a resolution of $4 \mathrm{~cm}^{-1}$. The wavenumbers were in the range of $2000-600 \mathrm{~cm}^{-1}$ for conducting fillers and $4000-600 \mathrm{~cm}^{-1}$ for neat TPU and TPU composites.

The X-ray diffraction (XRD) patterns of all samples were obtained on an Philips X'PERT (Philips, Germany) X-ray diffractometer, with $\mathrm{CuK} \alpha(\lambda=$ $0.154 \mathrm{~nm}$ ) radiation source operating at a voltage of $40 \mathrm{kV}$ and $30 \mathrm{~mA}$ current. The samples were evaluated in a $20^{\circ}$ range from 2 to $50^{\circ}$, at steps of $0.05^{\circ}$ and a time step of $1 \mathrm{~s}$. Mt, PPy and Mt-PPy samples were analyzed in powder form, while neat TPU and relative composites were in the form of compression molded disks.

The rheological properties of TPU and their physical mixtures were analyzed using dynamic oscillatory rheometry in the molten state through an Anton Paar MCR302 rheometer (Anton Paar GmbH, Germany). Dynamic frequency sweep test were conducted at $170^{\circ} \mathrm{C}$ with angular frequency range from 0.1 to $100 \mathrm{~Hz}$, in an oscillatory shear mode by using a $25 \mathrm{~mm}$ parallel plate with a gap around $1000 \mu \mathrm{m}$.

\section{Results and discussion}

\subsection{Characterization of conductive fillers}

The composition of samples, electrical conductivity and PPy content inserted in the Mt are summarized in Table 1. Mt-PPy.DBSA and Mt-PPy.Cl display higher PPy content (approximately $90 \mathrm{wt} \%$ of PPy) than those found by our recent study due to the higher Py amount used in the in situ polymerization

Table 1. Elemental analysis, PPy content and electrical conductivity of conductive filler (PPy.Cl, PPy.DBSA, Mt/PPy.Cl and Mt/PPy.DBSA)

\begin{tabular}{|c|c|c|c|c|c|}
\hline \multirow{2}{*}{ Samples } & \multicolumn{3}{|c|}{ Compositiont } & \multirow{2}{*}{$\begin{array}{l}\text { PPy content } \\
{[w t \%]}\end{array}$} & \multirow{2}{*}{$\begin{array}{c}\text { Electrical conductivity } \\
{\left[\mathrm{S} \cdot \mathrm{cm}^{-1}\right]}\end{array}$} \\
\hline & $\mathbf{C}$ & $\mathbf{H}$ & $\mathbf{N}$ & & \\
\hline $\mathrm{Mt}$ & 0.08 & 1.93 & 0.00 & 0.00 & $(4.26 \pm 0.34) \cdot 10^{-6}$ \\
\hline PPy.Cl & 55.04 & 3.52 & 16.14 & 100.00 & $0.15 \pm 0.02$ \\
\hline PPy.DBSA & 66.20 & 6.35 & 9.90 & 100.00 & $4.39 \pm 1.02$ \\
\hline $\mathrm{Mt} / \mathrm{PPy} . \mathrm{Cl}$ & 44.97 & 3.01 & 13.48 & 83.52 & $4.26 \pm 0.14$ \\
\hline Mt/PPy.DBSA & 56.75 & 5.81 & 8.92 & 90.10 & $10.03 \pm 0.89$ \\
\hline
\end{tabular}

Calculated from elemental analysis. 
process [41]. As expected, the electrical conductivity of PPy.DBSA $\left(4.4 \mathrm{~S} \cdot \mathrm{cm}^{-1}\right)$ is higher than that found for PPy.Cl $\left(0.2 \mathrm{~S} \cdot \mathrm{cm}^{-1}\right)$ due to the doping effect of DBSA molecules [41, 42]. In fact, the PPy.Cl sample was prepared in absence of protonic acid and the $\mathrm{HCl}$ that participates on the doping process was provided by the $\mathrm{FeCl}_{3}$ used as an oxidant.

This condition should be responsible for the lower conductivity value found for the PPy.Cl sample. The electrical conductivity values found for MtPPy.DBSA and Mt-PPy.Cl samples are seven and six orders of magnitude higher than that of neat Mt, respectively. Furthermore, Mt-PPy.Cl nanocomposite shows an increment in the electrical conductivity of one order of magnitude higher than that found for neat $\mathrm{PPy}-\mathrm{Cl}$, probably due to the doping effect of the Mt [41].

\subsection{Characterization of TPU/Mt-PPy.DBSA nanocomposites}

TPU/Mt-PPy.DBSA nanocomposites show a very sharp insulator-conductor transition and the electrical conductivity increased significantly with increasing the Mt-PPy.DBSA content, as observed in Figure 1. This behavior can be attributed to the formation of a continuous conductive Mt-PPy.DBSA network in the insulating polymer. On the other hand, the electrical conductivity of the systems containing $30 \mathrm{wt} \%$ of Mt-PPy.Cl, PPy.Cl and PPy.DBSA show electrical conductivities of $1.3 \cdot 10^{-4}, 5.4 \cdot 10^{-11}$ and $4.3 \cdot 10^{-10} \mathrm{~S} \cdot \mathrm{cm}^{-1}$, respectively, which were much lower than the value found for TPU/Mt-PPy.DBSA nanocomposites $\left(1.5 \cdot 10^{-2} \mathrm{~S} \cdot \mathrm{cm}^{-1}\right)$ at the same conductive filler content.

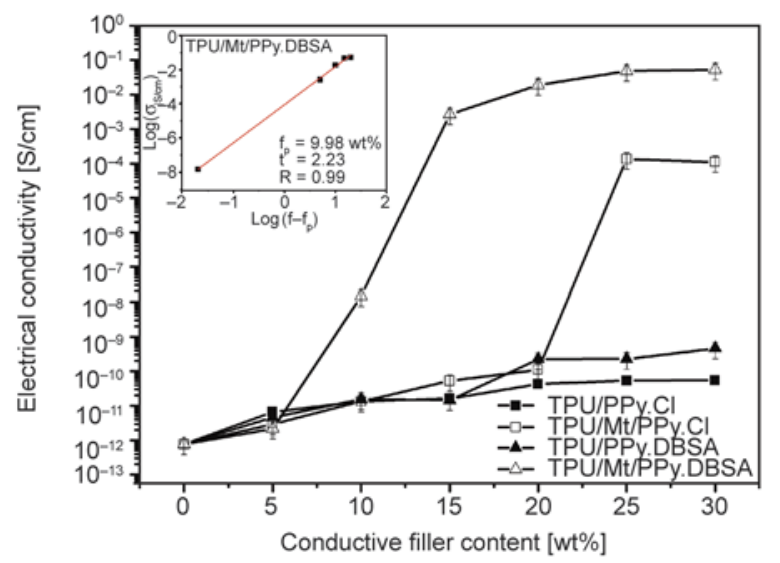

Figure 1. Effect of the conducting fillers content on electrical conductivity
For electrically percolating systems, the electrical conductivity $\sigma$ of a filled material follows a powerlaw relationship in the form of Equation (1):

$\sigma=\sigma_{0}\left(f-f_{\mathrm{p}}\right)^{\mathrm{t}}$

where $\sigma_{0}$ is a constant, $f$ is the content of conducting filler, $f_{\mathrm{p}}$ is its percolation threshold and $t$ is the critical exponent. The values of parameters $f_{\mathrm{p}}$ and $t$, as determined through the plot of $\log \sigma$ versus $\log \left(f-f_{\mathrm{p}}\right)$, of TPU/Mt-PPy.DBSA nanocomposites resulted to be $\sim 10 \mathrm{wt} \%$ and 2.2 , respectively. A critical exponent in the range from 2 to 4 is in agreement with the classical theory for tridimensional systems. On the other hand, TPU/Mt.PPy.Cl nanocomposites show a percolation threshold of $22.5 \mathrm{wt} \%$. The lower $f_{\mathrm{p}}$ value and higher electrical conductivity of TPU/Mt-PPy.DBSA nanocomposites with respect to TPU/Mt.PPy.Cl and TPU/PPy samples probably reflects the good dispersion of the conductive filler (Mt-PPy.DBSA) in the polymer matrix. These results are consistent with the morphological features of these materials, as it will be discussed later.

FESEM micrographs of cryogenically fractured samples with $20 \mathrm{wt} \%$ of conductive filler are shown in Figure 2. The microstructure of the TPU/PPy.Cl and TPU/PPy.DBSA blends revealed typical phase separation morphology with the presence of isolated PPy agglomerates in the TPU matrix. This morphology can explain the low electrical conductivity for these samples. On the other hand, TPU/MtPPy.Cl and TPU/Mt-PPy.DBSA nanocomposites present disperse agglomerates composed of conducting pathways, in which the disperse phase is better interconnected than in the case of TPU/PPy.Cl and TPU/PPy.DBSA blends. Furthermore, TEM image of TPU/Mt-PPy.DBSA nanocomposite (Figure 3) reveals a denser network formation of MtPPy.DBSA in the TPU matrix when compared with that found for Mt-PPy.Cl. The morphological difference of TPU/Mt-PPy.Cl and TPU/Mt-PPy.DBSA nanocomposites indicates that DBSA was able to induce the formation of conductive pathways in the TPU matrix, and consequently enhancing the electrical conductivity. This morphology can be attributed to the higher site-specific interaction between TPU matrix and Mt-PPy.DBSA.

The infrared spectra of neat TPU, TPU/PPy blends and TPU/Mt-PPy nanocomposites filled with $20 \mathrm{wt} \%$ 

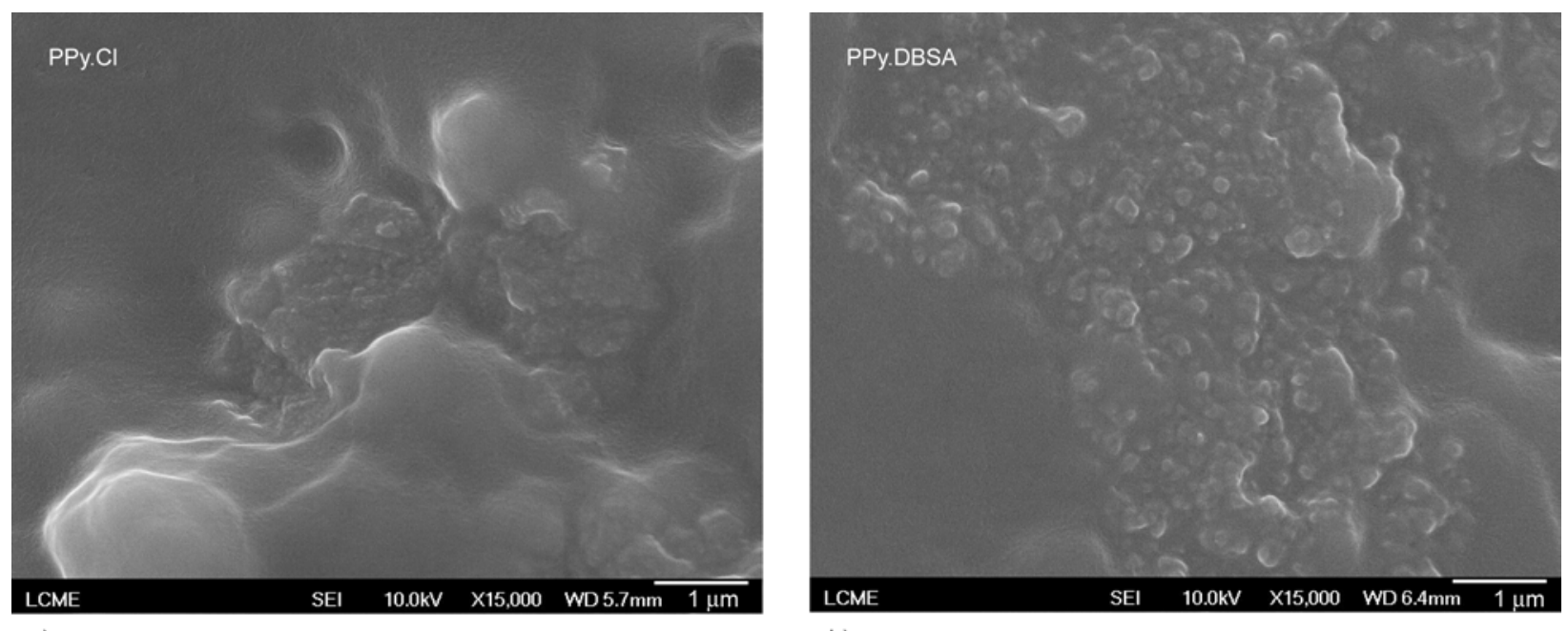

a)

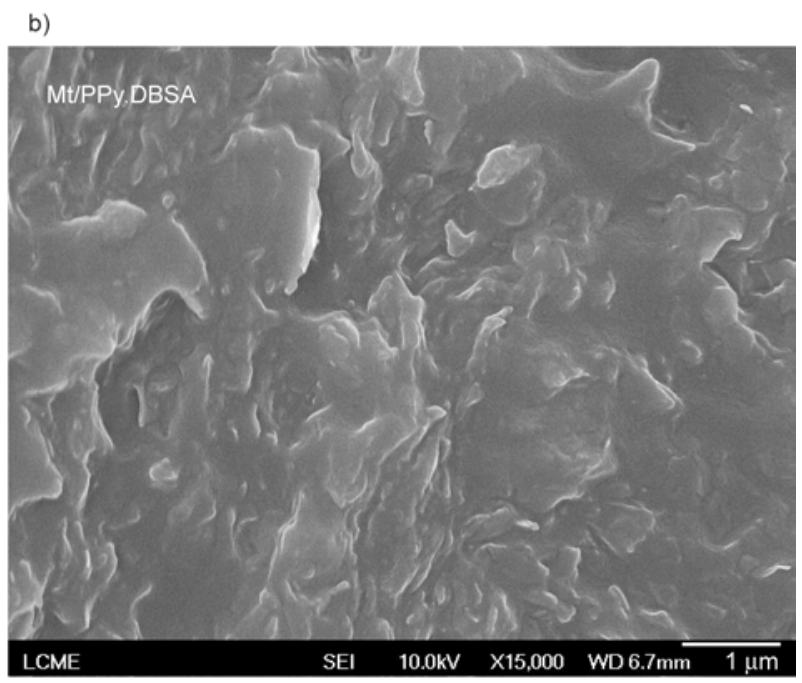

d)

c)

Figure 2. FESEM micrographs of cryogenically fractured samples with $20 \mathrm{wt} \%$ conductive for TPU/PPy.Cl (a), TPU/ PPy.DBSA (b), TPU/Mt-PPy.Cl (c) and TPU/Mt-PPy.DBSA nanocomposites (d)

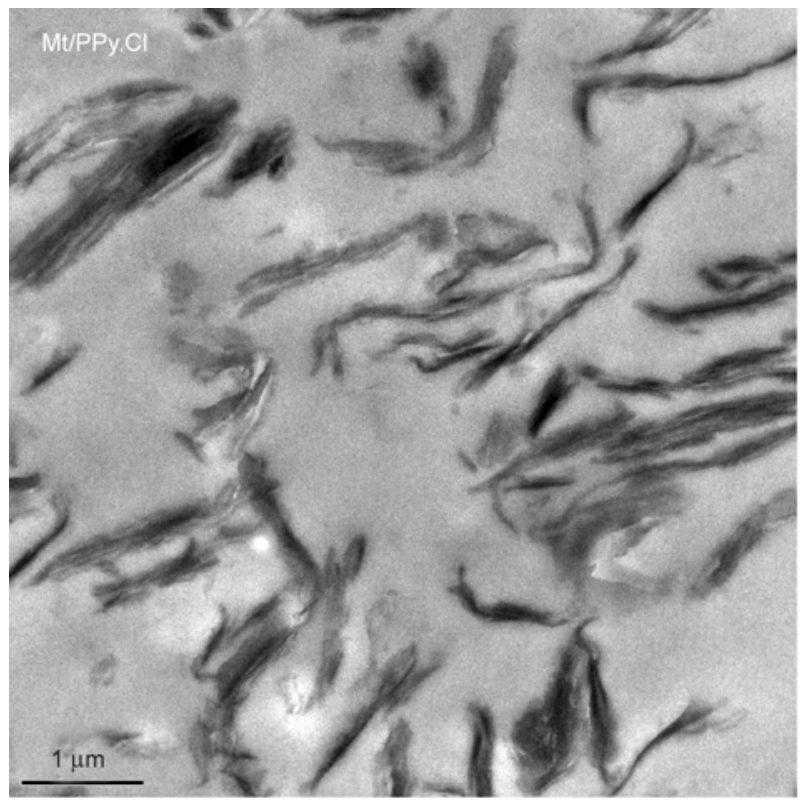

a)

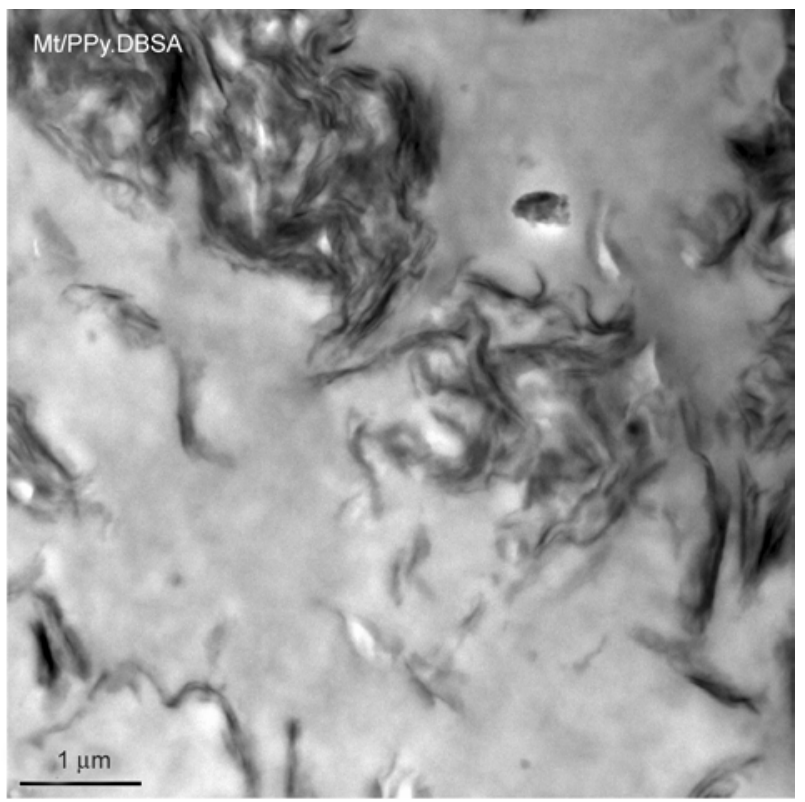

b)

Figure 3. TEM images of TPU/Mt-PPy.C (a) and Mt-PPy.DBSA (b) 

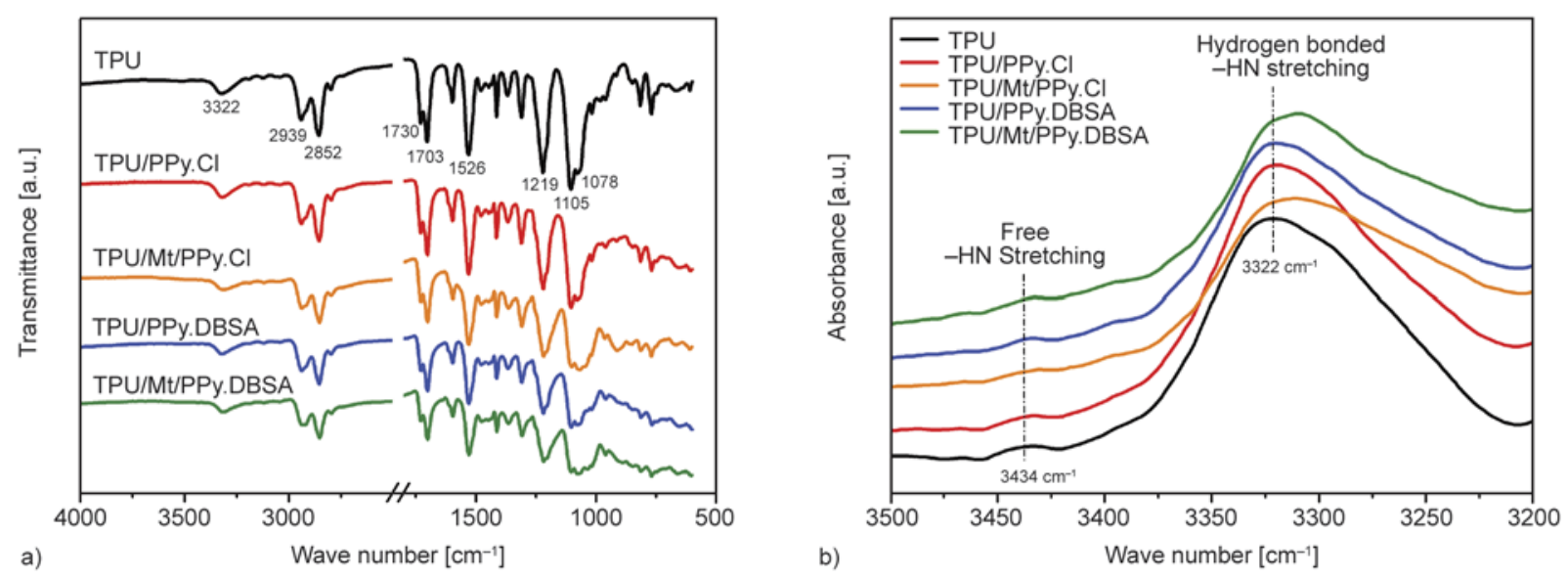

Figure 4. FTIR spectra of (a) pure TPU and physical mixtures with $20 \mathrm{wt} \%$ loading of conductive filler and (b) free and hydrogen bonded N-H stretching region

of conductive filler are shown in Figure 4. The absorption bands of neat TPU in the region of $3320 \mathrm{~cm}^{-1}$ and at around 2900 (2939 and $2852 \mathrm{~cm}^{-1}$ ) are assigned to the $\mathrm{N}-\mathrm{H}$ and $\mathrm{CH}_{2}$ absorption bands, respectively. The distinct bands that overlap intensively at 1730 and $1703 \mathrm{~cm}^{-1}$ are related to the free carbonyl and hydrogen-bonding absorption of the neat TPU molecules, respectively. The absorption band at $1526 \mathrm{~cm}^{-1}$ is attributed to $-\mathrm{NH}$ group of urethane while the bands at 1219 and $1105 \mathrm{~cm}^{-1}$ are assigned to the ether group [43-50].

The spectra of the TPU/PPy and TPU/Mt-PPy exhibited overlapped absorption bands of PPy and TPU. The band centered at $3320 \mathrm{~cm}^{-1}$, related to the bonded $-\mathrm{NH}$, was red-shifted to $3300 \mathrm{~cm}^{-1}$ for nanocomposites (Figure 4b) [51]. Furthermore, the band at $3435 \mathrm{~cm}^{-1}$ assigned to the free $-\mathrm{NH}$ group practically disappeared with the addition of the MtPPy.DBSA or Mt-PPy.Cl in the TPU matrix. These results suggest that the specific interaction between TPU and Mt-PPy.DBSA or Mt-PPy.Cl groups is higher than that observed for TPU and PPy.DBSA or PPy.Cl. An in-depth analysis of the infrared spectra in the range 1800 to $1650 \mathrm{~cm}^{-1}$ for neat TPU and its physical blends was carried out, as shown in Figure 5. The spectra with Gaussian deconvolution of absorption bands centered at 1730 and $1703 \mathrm{~cm}^{-1}$ are assigned to the free and site-specific interactions of the carbonyl group. As shown in Table 2, the absorption area ratio between free and bonded carbonyl groups (A1730/A1703) reduces significantly with increasing of PPy.DBSA, Mt-PPy.Cl and Mt-PPy.DBSA content, except for the PPy.Cl. The observed shifts in the $-\mathrm{NH}$ region (1350 to $1300 \mathrm{~cm}^{-1}$ ) and the reduction of the free carbonyl
Table 2. Ratio of the area under the peak of $\mathrm{C}=\mathrm{O}$ groups (free $\left(\mathrm{A}_{1730}\right)$ and hydrogen bonded $\mathrm{C}=\mathrm{O}\left(\mathrm{A}_{1703}\right)$ ), with $20 \mathrm{wt} \%$ loading of conductive filler

\begin{tabular}{|l|c|}
\hline \multicolumn{1}{|c|}{ Sample } & $\mathbf{A}_{(\mathbf{1 7 3 0 / 1 7 0 3 )}}$ \\
\hline TPU & 0.46 \\
\hline TPU/PPy.Cl & 0.48 \\
\hline TPU/Mt-PPy.Cl & 0.35 \\
\hline TPU/PPy.DBSA & 0.34 \\
\hline TPU/Mt-PPy.DBSA & 0.30 \\
\hline
\end{tabular}

absorption bands $\left(\mathrm{A}_{1730} / \mathrm{A}_{1703}\right)$ provide direct support for the fact that site-specific interaction between the $\mathrm{N}-\mathrm{H}$ and $\mathrm{C}=\mathrm{O}$ functional groups are operative in blends and/or nanocomposites containing PPy.DBSA, Mt-PPy.Cl and Mt-PPy.DBSA. These data also reveal that there are considerable fractions of both free and bonded carbonyl amine groups even when TPU is the dominant ( $80 \mathrm{wt} \%$ ) component. Moreover, the observed shifts and reduction of free carbonyl groups for TPU/Mt-PPy.DBSA are higher than those found for others blends and/or nanocomposites, suggesting higher interaction of TPU and MtPPy.DBSA. These results are consistent with those discussed in sections on morphology and electrical conductivity.

XRD curves of the neat TPU (Figure 6) exhibits a large and intense diffraction peak centered at $2 \theta=$ $19.98^{\circ}$ assigned to the reflection plane (110) with dvalue of $0.45 \mathrm{~nm}$. This diffraction pattern can be attributed to the irregular segments of the amorphous phase and, chains arranged on short-range of the TPU rigid phase, respectively $[52,53]$. According to Ramôa et al. [41] the neat Mt used in this study manifests a crystalline peak at $6.3^{\circ}(2 \theta)$ assigned to the periodicity in the (001) direction of neat $\mathrm{Mt}$ and $\mathrm{d}$-value is $1.4 \mathrm{~nm}$. The Mt diffraction peak and basal 

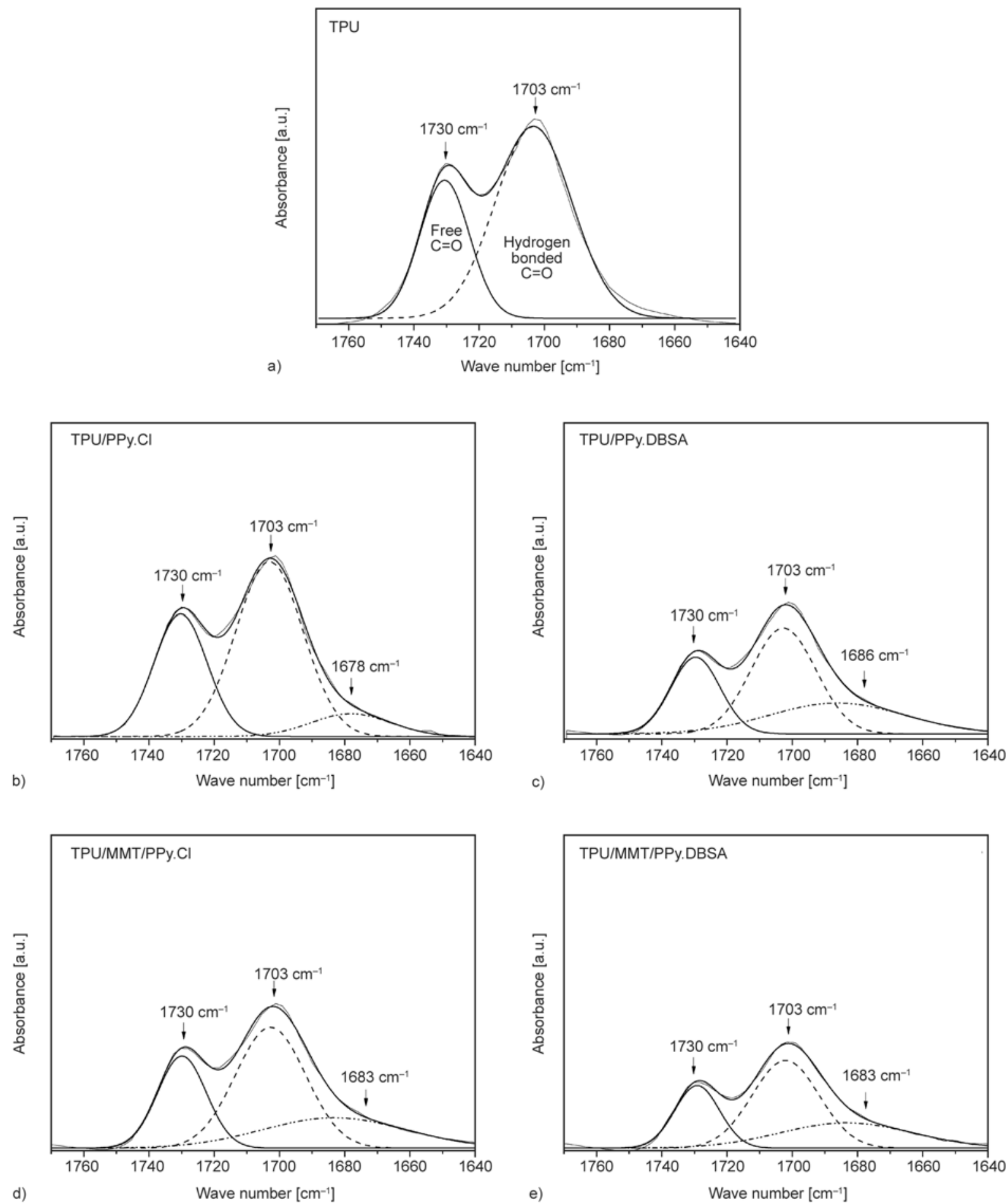

Figure 5. Deconvolution on the FTIR spectra in the free and hydrogen bonded carbonyl peaks $(\mathrm{C}=\mathrm{O}$ and $\mathrm{H}-\mathrm{C}=\mathrm{O})$ of pure TPU (a) and TPU composites with 20 wt\% loading of conductive filler PPy.Cl (b), PPy.DBSA (c), Mt-PPy.Cl (d), Mt-PPy.DBSA (e)

distance $\mathrm{d}_{(001)}$ for the TPU/Mt-PPy.Cl nanocomposites are shifted to $4.6^{\circ}(1.9 \mathrm{~nm})$, respectively, indicating an intercalation of Mt-PPy.Cl in the TPU matrix. However, the peak at $6.3^{\circ}$ practically disappeared for TPU/Mt-PPy.DBSA nanocomposites.

The storage $\left(G^{\prime}\right)$ and loss moduli $\left(G^{\prime \prime}\right)$ as a function frequency are shown in Figure 7 for neat TPU and its composites. At the lowest frequencies, neat TPU presents a liquid-like behavior $\left(G^{\prime \prime}>G^{\prime}\right)$. Furthermore, there is a transition from liquid to solid-like behavior $\left(G^{\prime \prime}<G^{\prime}\right)$ at a frequency of $31.8 \mathrm{~Hz}$, while for TPU/PPy.Cl and TPU/PPy.DBSA composites containing $5 \mathrm{wt} \%$ of $\mathrm{PPy} . \mathrm{Cl}$, this transition was observed at 81.7 and $81.5 \mathrm{~Hz}$, respectively. For both TPU/PPy 


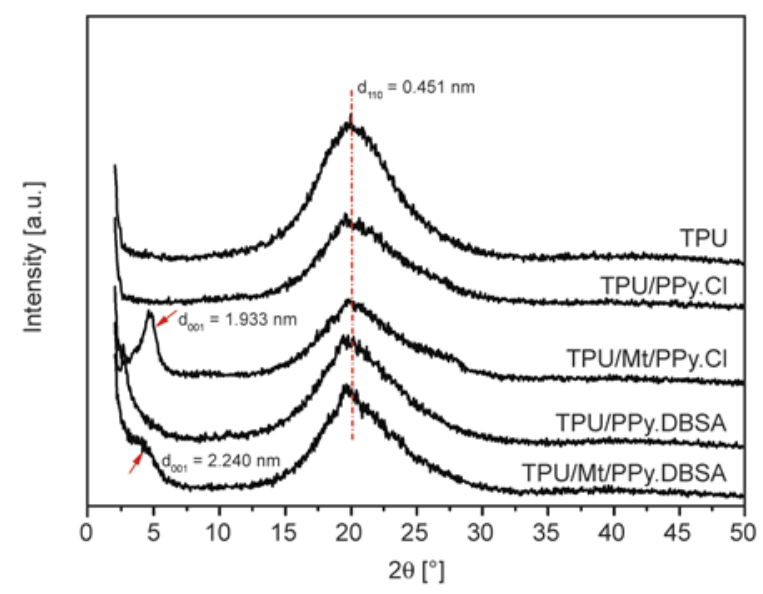

Figure 6. XRD patterns of pure TPU and TPU nanocomposites containing $20 \mathrm{wt} \%$ loading of conductive filler

blends, $G^{\prime}$ and $G^{\prime \prime}$ values decrease with increasing the amount of PPy, suggesting a certain degree of polymer matrix degradation. On the other hand, TPU/Mt-PPy.Cl and TPU/Mt -PPy.DBSA nanocomposites show a quite different behavior when

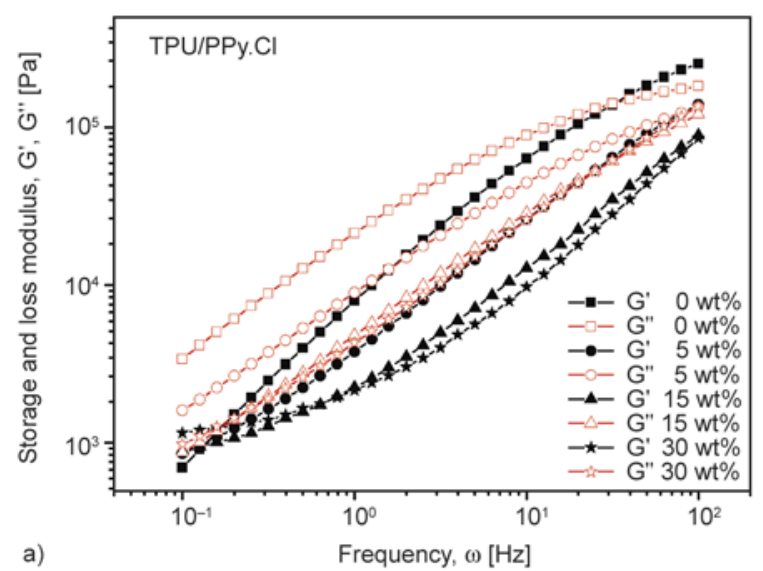

a)

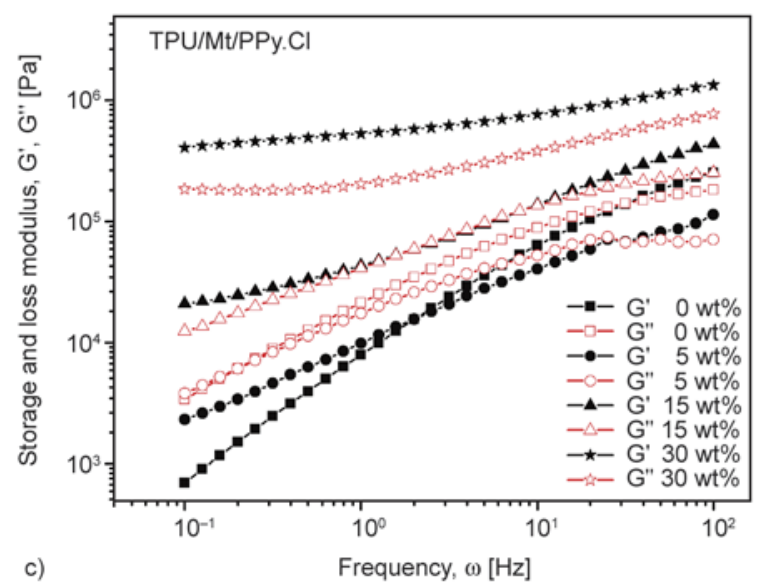

compared with those found for TPU/PPy blends. For both TPU/Mt-PPy nanocomposites, $G^{\prime}$ and $G^{\prime \prime}$ values increase with increasing the Mt-PPy content in the TPU matrix. The significant increase in the storage modulus indicates that TPU/Mt-PPy nanocomposites exhibit a pseudo-solid-like behavior. Moreover, TPU/Mt-PPy nanocomposites with $5 \mathrm{wt} \%$ of Mt-PPy content show a transition from liquid to solid-like behavior at frequencies higher than $31.8 \mathrm{~Hz}$, which is the same value observed for the neat TPU, while the values of $G^{\prime}$ becomes almost independent at lower frequency for nanocomposites containing $15 \mathrm{wt} \%$ of Mt-PPy. This behavior can be attributed to the percolative network formation, in which the conductive filler reduces the mobility of the TPU chain. The rheological percolative network increases the number of interfaces between conductive fillers, and thus an enhancement of the both elastic and viscous components is observed.

The loss tangent $(\tan \delta)$ curves as a function of frequency reported in Figure 8 can provide an insight
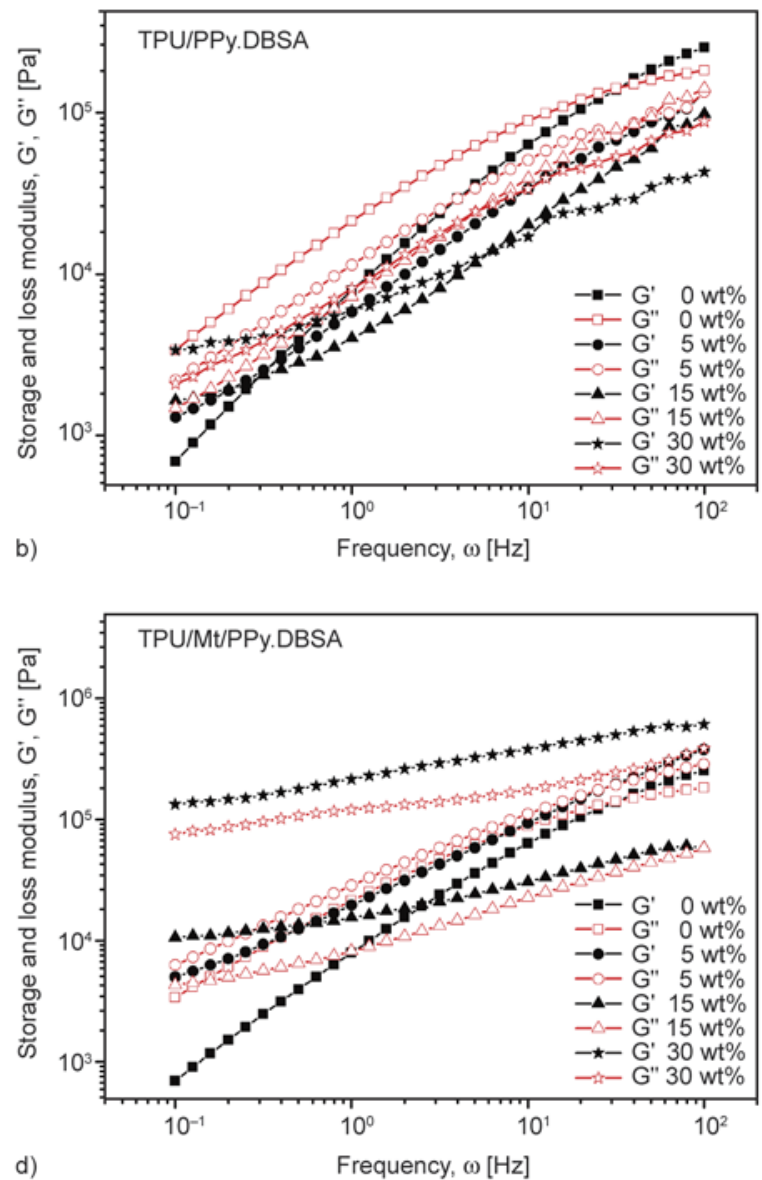

d)

Frequency, $\omega[\mathrm{Hz}]$

Figure 7. Storage modulus ( $G^{\prime}$, full points) and loss modulus ( $G^{\prime \prime}$, empty points) versus frequency $(\omega)$ at a temperature of $170^{\circ} \mathrm{C}$ for pure TPU and its composites containing $0,5,15$ and $30 \mathrm{wt} \%$ of various conductive fillers: $\mathrm{PPy} . \mathrm{Cl}$ (a), PPy.DBSA (b), Mt-PPy.Cl (c), Mt-PPy.DBSA (d) 

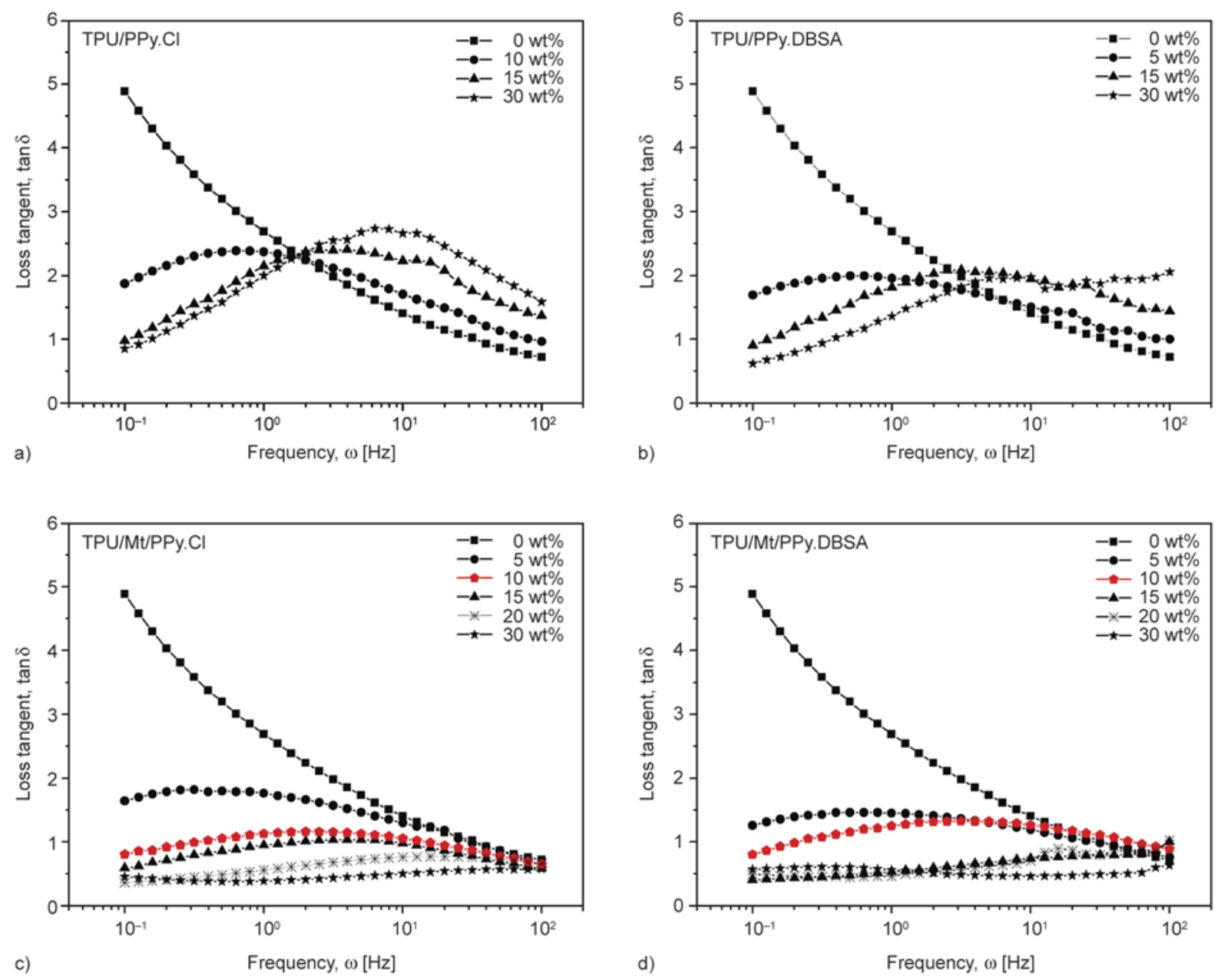

Figure 8. Loss tangent $\left(\tan \delta\right.$ ) versus frequency $(\omega)$ at a temperature of $170^{\circ} \mathrm{C}$ for pure TPU and its composites containing various percentages and types of conductive fillers: PPy.Cl (a), PPy.DBSA (b), Mt-PPy.Cl (c), Mt-PPy.DBSA (d)

on the site-specific interactions between the polymer matrix and conducting fillers [54, 55]. According to Han et al. [56], for a composite system with high-level of conducting phase agglomeration, a larger and more intense $\tan \delta$ curve with respect of neat insulating polymer can be observed. TPU/PPy.Cl and TPU/PPy.DBSA blends have shown this behavior, suggesting PPy agglomeration into TPU matrix. On the other hand, with increasing conducting filler, the TPU/Mt-PPy.Cl and TPU/Mt-PPy.DBSA nanocomposites show lower tan $\delta$ intensities when compared with the neat TPU, while for nanocomposites containing 15 and $30 \mathrm{wt} \%$ of Mt-Py $\tan \delta$ values are practically frequency independent. In addition, TPU/ Mt-PPy.DBSA composites exhibit lower $\tan \delta$ values than TPU/Mt-PPy.Cl, indicating better distribution and dispersion of Mt-PPy.DBSA in the TPU matrix. According to Pötschke et al. [57], this behavior supports the idea that site-specific interactions at the interface of insulating polymer matrix and conductive filler could be operative.
Figure 9 shows the storage modulus $G^{\prime}$ as a function of loss modulus $G^{\prime \prime}$ with frequency as a parameter for neat TPU and relative composites. These curves have been extensively used to investigate modifications in the structure of several polymeric systems at a fixed temperature [57-59]. According to McClory et al. [60] any change in the curve behavior of the composite compared with the neat PPy is an indication of network formation. It is observed that with increasing PPy.DBSA or PPy.Cl content, the variation of $G^{\prime}$ as a function of $G^{\prime \prime}$ for TPU/PPy.DBSA and TPU/PPy.Cl blends at lower frequency region (terminal zone) is different from that found for neat TPU. This behavior is characteristic of a system with heterogeneous structure. On the other hand, in the high frequency region (rubbery plateau) these curves are overlapped to that found for the neat TPU, which highlights the occurrence of a homogeneous structure. As expected, these mixtures should present a heterogeneous system behavior for all frequency regions. 

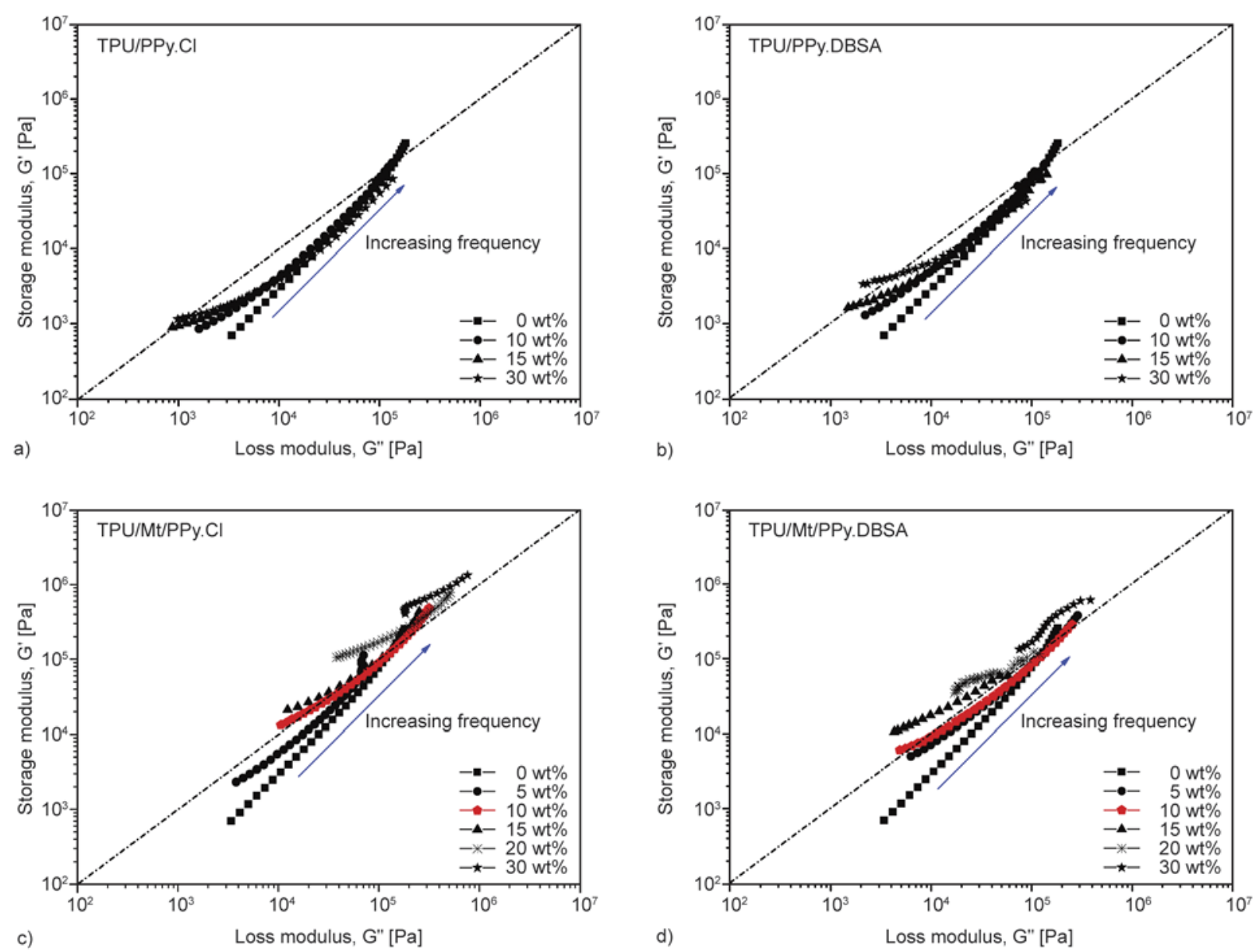

Figure 9. Han plot of storage modulus $\left(G^{\prime}\right)$ versus loss modulus $\left(G^{\prime \prime}\right)$ at a temperature of $170^{\circ} \mathrm{C}$ for pure TPU and its composites containing various percentages and types of conductive fillers: PPy.Cl (a), PPy.DBSA (b), Mt-PPy.Cl (c), Mt-PPy.DBSA (d)

According to Barick and Tripathy [59] the different behavior observed for TPU/PPy.Cl and TPU/ PPy.DBSA blends at higher and lower frequencies could be assigned to the difference of the dynamic relaxing processes for the neat TPU and mixtures. In addition, according to Han et al. [56] for a particular polymer system the applied shear stress at low frequency is not sufficient to disrupt the structure of the interconnected network due to the strong interactions between insulating polymer chains and conductive filler, resulting in a heterogeneous structure behavior below a critical shearing force. Above this critical point, with increasing the frequency, the shear stress is able to separate the conductive network structure and a homogeneous system behavior is observed. TPU/Mt-PPy.Cl and TPU/Mt-PPy.DBSA nanocomposites containing conductive filler loading up to $5 \mathrm{wt} \%$ show similar trend to those found for TPU/PPy.Cl and TPU/PPy.DBSA blends. However, above $10 \mathrm{wt} \%$ of Mt-PPy.DBSA and $15 \mathrm{wt} \%$ of Mt-PPy.Cl content, the curve slope of nanocom- posites is higher than those observed for neat TPU for all the investigated frequencies. This result indicates that TPU/Mt-PPy.DBSA and TPU/Mt-PPy.Cl composites are more heterogeneous when compared to TPU/PPy.Cl and TPU/PPy.DBSA blends, due to the presence of a strong three-dimensional conductive network, which is not disrupted with the shear force. These changes in the curve slope of MtPPy.DBSA nanocomposites suggest that the interphase interaction of the TPU matrix and MtPPy.DBSA are higher in descendent order of that found for Mt-PPy.Cl, PPy.DBSA and PPy.Cl fillers $[57,61]$.

\section{Conclusions}

A new electrical conductive nanocomposite based on thermoplastic polyurethane and montmorillonite/ dodecylbenzenesulfonic acid-doped polypyrrole (TPU/Mt-PPy.DBSA) with an electrical conductivity as high as $0.05 \mathrm{~S} \cdot \mathrm{cm}^{-1}$ was successfully prepared through melt mixing process using an internal mix- 
ing chamber. The structure and properties of the mixtures were strongly dependent on the site-specific interactions between the conductive filler and TPU chains. TPU/Mt-PPy.DBSA exhibits higher electrical conductivity and lower percolation threshold than TPU/Mt-PPy.Cl, TPU/PPy.Cl and TPU/PPy.DBSA mixtures. This behavior can be attributed to the strong interaction of Mt-PPy.DBSA particles and TPU matrix, which induces a better conductive network formation than those found for Mt-PPy.Cl, PPy.Cl and PPy.DBSA fillers. Furthermore, this synergistic effect can also be assigned to the presence of Mt that acts as a template for the PPy.DBSA, facilitating the formation of Mt-PPy.DBSA network in the TPU matrix. The results reported in this study prove that the morphology and electrical conductivity are significantly influenced by the composition of the conductive filler used in the melt mixing process, especially in the case of Mt-PPy.DBSA. Moreover, the present work reveals the potential use of MtPPy.DBSA as a new promising conductive filler for producing highly conductive polymer nanocomposites to be applied in several technological applications.

\section{Acknowledgements}

The authors gratefully acknowledge the financial support of the Conselho Nacional de Desenvolvimento Científico e Tecnológico - CNPq processo 400155/2014-1, Coordenação de Aperfeiçoamento de Pessoal de Ensino Superior - CAPES, and Fundação de Amparo à Pesquisa e Inovação do Estado de Santa Catarina - FAPESC. We are also very grateful to Central Electronic Microscopy Laboratory, (LCME-UFSC) for the microscopy analysis (FESEM).

\section{References}

[1] Yang C., Liu P., Zhao Y.: Preparation and characterization of coaxial halloysite/polypyrrole tubular nanocomposites for electrochemical energy storage. Electrochimica Acta, 55, 6857-6864 (2010).

DOI: $10.1016 /$ j.electacta.2010.05.080

[2] Yanilmaz M., Kalaoglu F., Karakas H., Sarac A. S.: Preparation and characterization of electrospun polyurethane-polypyrrole nanofibers and films. Journal of Applied Polymer Science, 125, 4100-4108 (2012). DOI: $10.1002 / a p p .36386$

[3] Pojanavaraphan T., Magaraphan R.: Fabrication and characterization of new semiconducting nanomaterials composed of natural layered silicates $\left(\mathrm{Na}^{+}-\mathrm{MMT}\right)$, natural rubber (NR), and polypyrrole (PPy). Polymer, 51, 1111-1123 (2010).

DOI: $\underline{10.1016 / j . p o l y m e r .2009 .07 .003}$
[4] Lee J-W., Serna F., Nickels J., Schmidt C. E.: Carboxylic acid-functionalized conductive polypyrrole as a bioactive platform for cell adhesion. Biomacromolecules, 7, 1692-1695 (2006). DOI: $10.1021 / \mathrm{bm} 060220 \mathrm{q}$

[5] Omastová M., Trchová M., Kovářová J., Stejskal J.: Synthesis and structural study of polypyrroles prepared in the presence of surfactants. Synthetic Metals, 138, 447-455 (2003). DOI: $10.1016 / \mathrm{S} 0379-6779(02) 00498-8$

[6] Reung-u-Rai A., Prom-Jun A., Prissanaroon-Ouajai W.: Synthesis of highly conductive polypyrrole nanoparticles via microemulsion polymerization. Journal of Metals, Materials and Minerals, 18, 27-31 (2008).

[7] Gurunathan K., Murugan A. V., Marimuthu R., Mulik U., Amalnerkar D.: Electrochemically synthesised conducting polymeric materials for applications towards technology in electronics, optoelectronics and energy storage devices. Materials Chemistry and Physics, 61, 173-191 (1999). DOI: $10.1016 / \mathrm{S} 0254-0584(99) 00081-4$

[8] Jiang L., Jun H-K., Hoh Y-S., Lim J-O., Lee D-D., Huh J-S.: Sensing characteristics of polypyrrole-poly (vinyl alcohol) methanol sensors prepared by in situ vapor state polymerization. Sensors and Actuators B: Chemical, 105, 132-137 (2005).

DOI: $10.1016 /$ j.snb.2003.12.077

[9] Merlini C., dos Santo Almeida R., D’Ávila M. A., Schreiner W. H., de Oliviera Barra G. M.: Development of a novel pressure sensing material based on polypyrrole-coated electrospun poly(vinylidene fluoride) fibers. Materials Science and Engineering: B, 179, 52-59 (2014).

DOI: $10.1016 /$ j.mseb.2013.10.003

[10] Li M., Li H., Zhong W., Zhao Q., Wang D.: Stretchable conductive polypyrrole/polyurethane (PPy/PU) strain sensor with netlike microcracks for human breath detection. ACS Applied Materials and Interfaces, 6, 1313-1319 (2014).

DOI: $10.1021 / \mathrm{am} 4053305$

[11] Hosseini S. H., Entezami A. A.: Conducting polymer blends of polypyrrole with polyvinyl acetate, polystyrene, and polyvinyl chloride based toxic gas sensors. Journal of Applied Polymer Science, 90, 49-62 (2003).

DOI: $10.1002 /$ app. 12492

[12] Brady S., Diamond D., Lau K-T.: Inherently conducting polymer modified polyurethane smart foam for pressure sensing. Sensors and Actuators A: Physical, 119, 398-404 (2005). DOI: $10.1016 /$ j.sna.2004.10.020

[13] Tjahyono A. P., Aw K. C., Travas-Sejdic J.: A novel polypyrrole and natural rubber based flexible large strain sensor. Sensors and Actuators B: Chemical, 166-167, 426-437 (2012). DOI: $10.1016 /$ j.snb.2012.02.083 
[14] Xu J., Zhu L., Bai Z., Liang G., Liu L., Fang D., Xu W.: Conductive polypyrrole-bacterial cellulose nanocomposite membranes as flexible supercapacitor electrode. Organic Electronics, 14, 711-718 (2013).

DOI: $10.1016 /$ j.orgel.2013.09.042

[15] Mi H., Zhang X., Ye X., Yang S.: Preparation and enhanced capacitance of core-shell polypyrrole/polyaniline composite electrode for supercapacitors. Journal of Power Sources, 176, 403-409 (2008).

DOI: $10.1016 /$ j.jpowsour.2007.10.070

[16] Olsson H., Nyström G., Strømme M., Sjödin M., Nyholm L.: Cycling stability and self-protective properties of a paper-based polypyrrole energy storage device. Electrochemistry Communications, 13, 869-871 (2011). DOI: 10.1016/j.elecom.2011.05.024

[17] Armelin E., Pla R., Liesa F., Ramis X., Iribarren J. I., Alemán C.: Corrosion protection with polyaniline and polypyrrole as anticorrosive additives for epoxy paint. Corrosion Science, 50, 721-728 (2008).

DOI: $10.1016 /$ j.corsci.2007.10.006

[18] Håkansson E., Amiet A., Nahavandi S., Kaynak A.: Electromagnetic interference shielding and radiation absorption in thin polypyrrole films. European Polymer Journal, 43, 205-213 (2007).

DOI: 10.1016/j.eurpolymj.2006.10.001

[19] Yavuz Ö., Ram M. K., Aldissi M., Poddar P., Srikanth H.: Polypyrrole composites for shielding applications. Synthetic Metals, 151, 211-217 (2005).

DOI: 10.1016/j.synthmet.2005.05.011

[20] Kim S. H., Jang S. H., Byun S. W., Lee J. Y., Joo J. S., Jeong S. H., Park M. J.: Electrical properties and EMI shielding characteristics of polypyrrole-nylon 6 composite fabrics. Journal of Applied Polymer Science, 87, 1969-1974 (2003).

DOI: 10.1002/app.11566

[21] Wallace G. G., Campbell T. E., Innis P. C.: Putting function into fashion: Organic conducting polymer fibres and textiles. Fibers and Polymers, 8, 135-142 (2007). DOI: $10.1007 / \mathrm{BF} 02875782$

[22] Gasana E., Westbroek P., Hakuzimana J., De Clerck K., Priniotakis G., Kiekens P., Tseles D.: Electroconductive textile structures through electroless deposition of polypyrrole and copper at polyaramide surfaces. Surface and Coatings Technology, 201, 3547-3551 (2006). DOI: $10.1016 /$ j.surfcoat.2006.08.128

[23] Xu H., Holzwarth J. M., Yan Y., Xu P., Zheng H., Yin Y., Li S., Ma P. X.: Conductive PPy/PDLLA conduit for peripheral nerve regeneration. Biomaterials, 35, 225235 (2014).

DOI: $10.1016 /$ j.biomaterials.2013.10.002

[24] Otero T. F., Cortés M. T.: Artificial muscles with tactile sensitivity. Advanced Materials, 15, 279-282 (2003). DOI: $10.1002 /$ adma.200390066

[25] Hara S., Zama T., Takashima W., Kaneto K.: Polypyrrole-metal coil composite actuators as artificial muscle fibres. Synthetic Metals, 146, 47-55 (2004). DOI: 10.1016/j.synthmet.2004.06.021
[26] Smela E.: Conjugated polymer actuators for biomedical applications. Advanced Materials, 15, 481-494 (2003).

DOI: $10.1002 / \mathrm{adma} .200390113$

[27] Peighambardoust S. J., Pourabbas B.: Preparation and characterization of nylon-6/PPy/MMT composite of nanocomposite. Journal of Applied Polymer Science, 106, 697-705 (2007).

DOI: 10.1002/app.26709

[28] Peighambardoust S. J., Pourabbas B.: Synthesis and characterization of conductive polypyrrole/montmorillonite nanocomposites via one-pot emulsion polymerization. Macromolecular Symposia, 247, 99-109 (2007). DOI: $10.1002 /$ masy. 200750112

[29] Sevil B., Zuhal K.: Synthesis and characterization of polypyrrole nanoparticles and their nanocomposites with poly(propylene). Macromolecular Symposia, 295, 5964 (2010).

DOI: $10.1002 /$ masy.200900164

[30] Ashraf S. M., Ahmad S., Riaz U.: Pseudothermoset blends of poly (methyl methacrylate) and polypyrrole morphological, thermal, and conductivity studies. Journal of Applied Polymer Science, 93, 82-91 (2004). DOI: 10.1002/app.20404

[31] Mahmud H. N. M. E., Kassim A., Zainal Z., Yunus W. M. M.: Fourier transform infrared study of polypyrrolepoly(vinyl alcohol) conducting polymer composite films: Evidence of film formation and characterization. Journal of Applied Polymer Science, 100, 41074113 (2006).

DOI: $10.1002 / a p p .23327$

[32] Kotal M., Srivastava S. K., Paramanik B.: Enhancements in conductivity and thermal stabilities of polypyrrole/polyurethane nanoblends. Journal of Physical Chemistry C, 115, 1496-1505 (2011).

DOI: $10.1021 / j p 1081643$

[33] Muller D., Garcia M., Salmoria G. V., Pires A. T. N., Paniago R., Barra G. M. O.: SEBS/PPy.DBSA blends: Preparation and evaluation of electromechanical and dynamic mechanical properties. Journal of Applied Polymer Science, 120, 351-359 (2011).

DOI: 10.1002/app.33141

[34] Omastová M., Košina S., Pionteck J., Janke A., Pavlinec J.: Electrical properties and stability of polypyrrole containing conducting polymer composites. Synthetic Metals, 81, 49-57 (1996). DOI: 10.1016/0379-6779(96)80228-1

[35] Omastová M., Pionteck J., Košina S.: Preparation and characterization of electrically conductive polypropylene/polypyrrole composites. European Polymer Journal, 32, 681-689 (1996). DOI: $10.1016 / 0014-3057(95) 00206-5$

[36] Boukerma K., Piquemal J-Y., Chehimi M. M., Mravčáková M., Omastová M., Beaunier P.: Synthesis and interfacial properties of montmorillonite/polypyrrole nanocomposites. Polymer, 47, 569-576 (2006). DOI: $10.1016 /$ j.polymer.2005.11.065 
[37] Zhu D., Bin Y., Oishi K., Fukuda Y., Nakaoki T., Matsuo M.: Conductive composite materials of polyethylene and polypyrrole with high modulus and high strength. Macromolecular Symposia, 214, 197-216 (2004).

DOI: 10.1002/masy.200451014

[38] Mravčáková M., Omastová M., Pötschke P., Pozsgay A., Pukánszky B., Pionteck J.: Poly(propylene)/montmorillonite/polypyrrole composites: Structure and conductivity. Polymers for Advanced Technologies, 17, 715-726 (2006).

DOI: $10.1002 /$ pat.765

[39] Boubakri A., Haddar N., Elleuch K., Bienvenu Y.: Impact of aging conditions on mechanical properties of thermoplastic polyurethane. Materials and Design, 31, 4194-4201 (2010).

DOI: $10.1016 / \mathrm{j}$. matdes.2010.04.023

[40] Fernández-d'Arlas B., Khan U., Rueda L., Coleman J. N., Mondragon I., Corcuera M. A., Eceiza A.: Influence of hard segment content and nature on polyurethane/ multiwalled carbon nanotube composites. Composites Science and Technology, 71, 1030-1038 (2011). DOI: 10.1016/j.compscitech.2011.02.006

[41] Ramôa S. D. A. S., Barra G. M. O., Merlini C., Schreiner W. H., Livi S., Soares B. G.: Production of montmorillonite/polypyrrole nanocomposites through in situ oxidative polymerization of pyrrole: Effect of anionic and cationic surfactants on structure and properties. Applied Clay Science, 104, 160-167 (2015). DOI: 10.1016/j.clay.2014.11.026

[42] Mravčáková M., Omastová M., Olejníková K., Pukánszky B., Chehimi M. M.: The preparation and properties of sodium and organomodified-montmorillonite/ polypyrrole composites: A comparative study. Synthetic Metals, 157, 347-357 (2007).

DOI: 10.1016/j.synthmet.2007.04.005

[43] Menes O., Cano M., Benedito A., Giménez E., Castell P., Maser W. K., Benito A. M.: The effect of ultra-thin graphite on the morphology and physical properties of thermoplastic polyurethane elastomer composites. Composites Science and Technology, 72, 1595-1601 (2012). DOI: 10.1016/j.compscitech.2012.06.016

[44] Bistričić L., Baranović G., Leskovac M., Bajsić E. G.: Hydrogen bonding and mechanical properties of thin films of polyether-based polyurethane-silica nanocomposites. European Polymer Journal, 46, 1975-1987 (2010).

DOI: 10.1016/j.eurpolymj.2010.08.001

[45] Russo P., Lavorgna M., Piscitelli F., Acierno D., Di Maio L.: Thermoplastic polyurethane films reinforced with carbon nanotubes: The effect of processing on the structure and mechanical properties. European Polymer Journal, 49, 379-388 (2013).

DOI: 10.1016/j.eurpolymj.2012.11.008

[46] Pattanayak A., Jana S. C.: Properties of bulk-polymerized thermoplastic polyurethane nanocomposites. Polymer, 46, 3394-3406 (2005). DOI: $10.1016 /$ j.polymer.2005.03.021
[47] Petcharoen K., Sirivat A.: Electrostrictive properties of thermoplastic polyurethane elastomer: Effects of urethane type and soft-hard segment composition. Current Applied Physics, 13, 1119-1127 (2013). DOI: $10.1016 /$ j.cap.2013.03.005

[48] Ferry A., Jacobsson P., van Heumen J. D., Stevens J. R.: Raman, infra-red and D.S.C. studies of lithium coordination in a thermoplastic polyurethane. Polymer, 37, 737-744 (1996).

DOI: $10.1016 / 0032-3861(96) 87248-X$

[49] Yilgor I., Yilgor E., Guler I. G., Ward T. C., Wilkes G. L.: FTIR investigation of the influence of diisocyanate symmetry on the morphology development in model segmented polyurethanes. Polymer, 47, 4105-4114 (2006). DOI: 10.1016/j.polymer.2006.02.027

[50] Van Heumen J. D., Stevens J. R.: The role of lithium salts in the conductivity and phase morphology of a thermoplastic polyurethane. Macromolecules, 28, 42684277 (1995).

DOI: $10.1021 / \mathrm{ma} 00116 \mathrm{a} 030$

[51] Barick A. K., Tripathy D. K.: Effect of organoclay on the morphology, mechanical, thermal, and rheological properties of organophilic montmorillonite nanoclay based thermoplastic polyurethane nanocomposites prepared by melt blending. Polymer Engineering and Science, 50, 484-498 (2010).

DOI: $10.1002 /$ pen. 21556

[52] Barick A. K., Tripathy D. K.: Preparation and characterization of carbon nanofiber reinforced thermoplastic polyurethane nanocomposites. Journal of Applied Polymer Science, 124, 765-780 (2012).

DOI: 10.1002/app.35066

[53] Barick A. K., Tripathy D. K.: Preparation, characterization and properties of acid functionalized multi-walled carbon nanotube reinforced thermoplastic polyurethane nanocomposites. Materials Science and Engineering: B, 176, 1435-1447 (2011).

DOI: $10.1016 /$ j.mseb.2011.08.001

[54] Pistor V., Lizot A., Fiorio R., Zattera A. J.: Influence of physical interaction between organoclay and poly(ethylene-co-vinyl acetate) matrix and effect of clay content on rheological melt state. Polymer, 51, 5165-5171 (2010).

DOI: $10.1016 /$ j.polymer.2010.08.045

[55] Hyun Y. H., Lim S. T., Choi H. J., John M. S.: Rheology of poly(ethylene oxide)/organoclay nanocomposites. Macromolecules, 34, 8084-8093 (2001).

DOI: $10.1021 / \mathrm{ma} 002191 \mathrm{~W}$

[56] Han S-I., Lim J. S., Kim D. K., Kim M. N., Im S. S.: In situ polymerized poly(butylene succinate)/silica nanocomposites: Physical properties and biodegradation. Polymer Degradation and Stability, 93, 889-895 (2008). DOI: 10.1016/j.polymdegradstab.2008.02.007

[57] Pötschke P., Fornes T. D., Paul D. R.: Rheological behavior of multiwalled carbon nanotube/polycarbonate composites. Polymer, 43, 3247-3255 (2002). DOI: $10.1016 / \mathrm{S} 0032-3861(02) 00151-9$ 
[58] Di Y., Iannace S., Di Maio E., Nicolais L.: Nanocomposites by melt intercalation based on polycaprolactone and organoclay. Journal of Polymer Science Part B: Polymer Physics, 41, 670-678 (2003).

DOI: $10.1002 /$ polb. 10420

[59] Barick A. K., Tripathy D. K.: Nanostructure morphology and dynamic rheological properties of nanocomposites based on thermoplastic polyurethane and organically modified montmorillonite. Polymer Bulletin, 66, 1231-1253 (2011).

DOI: $10.1007 / \mathrm{s} 00289-010-0395-6$
[60] McClory C., McNally T., Baxendale M., Pötschke P., Blau W., Ruether M.: Electrical and rheological percolation of PMMA/MWCNT nanocomposites as a function of CNT geometry and functionality. European Polymer Journal, 46, 854-868 (2010).

DOI: $10.1016 /$ j.eurpolymj.2010.02.009

[61] Lee D., Lee S-H., Kim S., Char K., Park J. H., Bae Y. H.: Micro-phase-separation behavior of amphiphilic polyurethanes involving poly(ethylene oxide) and poly (tetramethylene oxide). Journal of Polymer Science Part B: Polymer Physics, 41, 2365-2374 (2003). DOI: $10.1002 /$ polb.10504 